UDC 364-5:159.9:316

\title{
LIVED EXPERIENCE OF PARTICIPATION IN DAILY OCCUPATIONS AMONG OLDER PEOPLE LIVING IN SOCIAL HOUSE IN ARMENIA
}

\section{AUTHORS' DATA:}

Zaruhi Harutyunyan, Researcher

Chair of Speech and Rehabilitative Therapy, Khachatur Abovyan Armenian State Pedagogical University Lecturer

Contacts: $\underline{\text { h.zaruhi@gmail.com }}$

Annika Öhman, OT, PhD Associate professor

Department of Health, Medicine and Caring Sciences, Division of Prevention, Rehabilitation and Community Medicine, Linköping University, Sweden

Associate professor

Contacts: annika.ohman@liu.se

Mandana Fallahpour, OT, PhD Assistant professor

Department of Neurobiology, Care Sciences and Society, Division of Occupational Therapy, Karolinska Institutet, Stockholm, Sweden

Assistant professor

Contacts: mandana.fallahpour@ki.se

\begin{abstract}
The aim of this qualitative study is to explore the lived experience of participation in daily occupations of older people living on Social House in Armenia

A total of eight participants (1 male, 7 female) who lived in social house in Yerevan, Armenia were in-depth interviewed in this study. The Empirical Phenomenological Perspective method (Karlsson,1993) was applied for analysing the interviews to explore the meaning structure of participation in daily occupations in social house as expressed by participants' lived experiences.
\end{abstract}


Findings has identified three main characteristics of participation in daily occupations of eight older people living in Social House: Change in place - change in life; being dependent as doer - not free in making choices; Lack of environmental possibilities in daily living.

The findings of the study highlighted older people's personal perceptions of current living place and importance of supportive environmental conditions which facilitate or challenge their participation in daily occupations. Subjective perception of the current place of living and experienced changes in daily occupation were identified among older people living in social house, which limited their possibilities to choose and maintain autonomy in daily occupations and in their social participation.

Key words: aging, participation, daily occupations, older people, social house, occupational therapy.

\section{INTRODUCTION}

Being old does not mean being sick, but for healthy ageing it is important to enable older people to take an active part in daily life, to enjoy an independent and good quality of life (Maltby, 2004).

Like many other countries, Armenia is also considered as an aging country since about 14.6 percent of Armenia's population is aged 60 or over (UNPD WPP, 2010; UNFPA, 2013) and the responsibility of the society to ensure that older people could achieve meaning, quality of life, health, happiness and well-being, and continue to develop their own occupational potential, shape their community or participate in daily life in ways that are valuable and valued (Wilcock, 2005). Moreover, the quality of living environment is particularly important for older people, given that they spend a vast majority of their time in their home and many have spent most of their lives in the same neighbourhood (SEU, 2006). Home and neighbourhood environment effect on participation in everyday life and independence of older people, since older people experienced that their home is the locus and origin of performance-oriented and togetherness-oriented participation in everyday life (Haak, 2006; Arvidsson, Granlund \& Tyberg, 2008).

Therefore, participation in daily life, being able to engage in daily occupation, is essential for all human existence (Wilcock, 1998) and has a positive influence on health and wellbeing (Brundtland, 1999; WHO, 2001). But life changes in older ages, like moving from private home 
to social house or other residential arrangements, may cause disruption in their daily routines and activities. But as an engagement in daily occupations has an overall impact on people's health and wellbeing (Eales, Keating \& Damsma, 2001; Christiansen \& Townsend, 2004) and people's engagement in goal-directed and meaningful occupation is seen as a vital part of active aging and lived experience (Law, 2002; Rioux, 2005; Haak, Dahlin-Ivanoff, Fange, Sixsmith et al., 2007), therefore, it is important to find possibilities for engagement in daily occupations and be adapted to life's challenges.

Theoretical literature has stressed the importance of environment that facilitates or inhibits participation in daily life among different populations (Law, 2002; Kielhofner, 2008;). Previous empirical literature has also stressed on the influence of home and neighbourhood environment in participation and independence among older people (Husserl, 1970; Haak, 2006; Haak, Fange, Iwarsson \& Ivanoff, 2007).

However, there is still lack of knowledge regarding how older people who live in social house experience their participation in daily occupations in Armenia.

\section{LITERATURE REVIEW}

\section{Aging, participation in daily occupations of older people}

Aging is an accumulation of changes in a person over time, general starting from 65 years of age (Heim, Wehnelt, Grande, Huber et al., 2013). Older people while participating in daily life and daily occupations remain their ability to control and manage different life situations (WHO, 2012).

According to the International Classification of Functioning, Disability and Health (ICF) participation defined as "involvement in a life situation" or as "the lived experiences" of people in the actual context in which they live" (WHO, 2001; WHO, 2012) which is important aspect of human life in health and well-being. The concept of occupational participation used by the Model of Human Occupation (MOHO) refers to "the engagement in work, play, or activities of daily living that are a part of socio-cultural context and are desired and/ or necessary to individual's well-being" (Lilja, 2000; Kielhofner, 2008). Participation in different areas of daily occupations is essential for all human existence (van Haitsma, Lawton, Kleban, Klapper et al., 1997) and for a positive influence on well-being. At the same time, for facilitating the participation of older people in daily life the social and physical environment, in exacting social attitudes and accessibility of support are mainly important aspects to take into consideration. 


\section{Home as an important environment for participation among older people}

Home considered to be the origin for participation both out of the home and within the home (Haak, 2006), and is strongly linked to independence and participation in daily life (Haak, Fange, Iwarsson \& Ivanoff, 2007).

For older people home should provide adequate, accessible, and personalized space to facilitate performing their daily routine and fulfilling their roles and responsibilities (Percival, 2002), which also considered as a familiar place, in a familiar location where they know others and feel in control of their lives (Davison, Kendig, Stephens, \& Merrill, 1993; Bowling, 2005).

Home environment offers a range of opportunities to choose what to do. It also provides resources to sustain individuals' motivation and facilitate their participation in daily life. The relationship between humans and their environment is intimate and reciprocal impacting on what people do and how they do it (Albert, 2000). From this point of view, it is vital to understand the environmental impact on people's life and well-being as well as challenges in order to manage their life and involvement in the actual context of the life situations in which they live (WHO ICFCY, 2001)

\section{Social house, participation and elderly}

The concept of "social housing" refers to housing owned by local authorities or registered social landlords such as housing associations aimed at supporting low-income, homeless people regulated by housing legislation (Balchin \& Rhoden, 1995). For older people home has a great importance and particular meaning, which is more than being as a physical environment, it is an easy reach to many of his/her daily needs (Guse \& Masesar, 1999). Therefore, it is important to focus on housing for older people and investigate their participation in daily occupations, which is considered to be vital for successful ageing (Wilcock, 2005).

Concluded literature review regarding the studied phenomenon revealed that limited research is performed regarding old people's experiences of participation in daily life who live in social house in general and particularly in Armenia. Taking into consideration the fact that older people spend much of their time in their home (Adams, 2008) and home has significant importance in older age, understanding the lived experiences of participation in daily life of older people in Armenia could be of great value while considering their environmental issues regarding their participation in daily life and wellbeing. 
Therefore, this study focused on exploring the lived experience of participation in daily occupations among older people living in social house in Armenia.

\section{METHODS}

Phenomenological approach was used (Karlsson,1993) to explore the lived experience of participation in daily occupations among older people living in social house in Yerevan, Armenia which is concerned with the life world or human experience as it is lived. The focus was toward illuminating details and seemingly trivial aspects within experience that may be taken for granted in people's lives (Husserl, 1970), with an aim of creating meaning and achieving a sense of understanding (Wilson \& Hutchinson, 1991).

The EPP method was used for data collection and analysis of the data from the interviews which was a qualitative, interpretative and descriptive method (Karlsson, 1993). The psychological perspective was replaced by an occupational perspective that was used while focusing on experience of participation in daily occupations among older people living in Social House.

\section{Participants}

Eight participants were included in the study from 66 to 80 years old, living in social house in Yerevan and information about the participants is presented in Table 1. Purposive sampling method (Depoy \& Gitlin, 1998) was used for participants' selection by the following inclusion criteria:

(1) Living at social house for a one year or more ( $\geq 1$ year), this time has been considered as a time for person to adapt to the new environment to share their lived experience of participation in social house;

(2) Not being diagnosed as dementia or chronic cognitive decline, in order to be able to communicate and respond to the questions of interviewer;

(3) Being able to respond the questions and describe their experiences;

(4) Agreed to participate in the study and share their experiences. 
Table 1. Demographic data of participants

\begin{tabular}{|l|l|l|l|l|l|l|l|l|}
\hline & $\begin{array}{c}\text { Participant } \\
\mathbf{1}\end{array}$ & \multicolumn{1}{|c|}{$\begin{array}{c}\text { Participant } \\
\mathbf{2}\end{array}$} & $\begin{array}{c}\text { Participant } \\
\mathbf{3}\end{array}$ & $\begin{array}{c}\text { Participant } \\
\mathbf{4}\end{array}$ & $\begin{array}{c}\text { Participant } \\
\mathbf{5}\end{array}$ & $\begin{array}{c}\text { Participant } \\
\mathbf{6}\end{array}$ & $\begin{array}{c}\text { Participant } \\
\mathbf{7}\end{array}$ & $\begin{array}{c}\text { Participant } \\
\mathbf{8}\end{array}$ \\
\hline Gender & Female & Female & Female & Female & Female & Female & Female & Male \\
\hline Education & Higher & Higher & Secondary & Secondary & Higher & Secondary & Vocational & Higher \\
\hline Marital status & Widow & Widow & Single & Single & Single & Single & Single & Divorced \\
\hline $\begin{array}{l}\text { Employment } \\
\text { history }\end{array}$ & 43 & 4 & 20 & 38 & 30 & 31 & 35 & 32 \\
\hline $\begin{array}{l}\text { Time for } \\
\text { living in } \\
\text { Social House }\end{array}$ & 4 years & 4 years & 4 years & 1 year & 3,5 year & 3 years & 2 years & 1,5 year \\
\hline
\end{tabular}

\section{Data collection}

In-depth interviews with eight participants (both genders) were conducted living in a social house in Yerevan. The interview questions were open-ended based on interview guide which was designed and used during data collection (Kvale, 1991). The interviews addressed experience of participation in daily occupations and personal meanings of performed daily activities. All the interviews were tape-recorded, lasting about 45-60 minutes of each. Field notes have been used as a validation of the participants' narratives to help the researcher understand their described lifeworld experiences during the analysis.

\section{Data analysis}

The Empirical Phenomenological Perspective (EPP) method was used for analysing the data collected from the interviews (Karlsson, 1993) which is a qualitative, descriptive, and interpretive analysis that aims to describe the essence, structure, and characteristics of the studied phenomenon based on participants' life-world experiences. The psychological perspective has been replaced by an occupational perspective that focuses on older people's lived experiences of participation in daily life while living in social house.

The tape-recorded interviews of 8 participants ( 8 protocols) have been transcribed word for word and analysed using five steps of the EPP method. As the first step the data from all of the 
interviews was read for understanding how older people experienced their participation in daily occupations. In the second step of the analysis the interviews have been reread for identifying all the meaning units in the interview and where there was a shift in the meanings. In the third step each meaning unit have been interpreted in light of all of data from the participant' and the phenomenon under the study. The focus has been on the meaning imbued by the participants. In the fourth step, the interpreted meaning units into a "situated structure of meaning" were synthesized and characteristics arranged to best describe the essence of the different characteristics and how they were related to each other, focusing on the meaning of performing or not performing varied daily occupations. As with the fifth step, this step also involved returning to the original data to ensure that relevant characteristics were not overlooked. To ensure credibility the researcher moved back and forth while interpretation and obtaining the data for each participant (Karlsson, 1993).

\section{Trustworthiness}

Trustworthiness of the analysis was examined with the "horizontal consistency of interpretations" (Karlsson, 1993) by making sure that interpretation of each interview was consistent with the meaning uncovered across all interviews, this means that parts were interpreted in the light of all data. Trustworthiness has been addressed via reflexive processes in the form of field notes (Depoy \& Gitlin, 1998), and phenomenological reduction has been implemented by the researcher. Peer review and discussion with supervisor were done to increase the credibility of the findings.

\section{Ethical considerations}

The participants have been provided with written and verbal information about the study and their participation. Written consent was obtained from all participants. The participants were free to quit the project whenever they would like and decided to do. The study has been approved by the Mission Armenia NGO which was responsible organization for providing services for older people living in Social House.

\section{FINDINGS}

The phenomenon of participation in daily occupations among older people living in the social house compromised a meaning structure consisting of three main characteristics and subcharacteristics (Table 2). 
The first characteristic, "Change in place-change in life" expressed the participants" experience of being connected to former living place and did not feeling secure and safe in daily occupations. The second characteristic, "being dependent as a doer-not free in making choices" expressed the participants' experience of difficulties and lacking in choices to do desired daily activities. The third characteristic, "lack of environmental possibilities in daily living" expressed that the participants limited in performing daily occupations by themselves, need support and felt isolated.

The characteristics and sub-characteristics of the phenomenon were described and exemplified using the participants' quotes from interviews.

Table 2. three main characteristics and sub-characteristics

(1). Change in place - change in life

1.1 Strong feeling of being home-lost - stay connected to former home

1.2 Important to feel safe and secure

(2). Being dependent as doer - not free in making choices

2.1 Problems in sharing with others in daily living

2.2 Financial problems to do desired activities

(3). Lack of environmental possibilities in daily living

3.1. Lack of supportive environment

3.2 Need to be get support

3.3 Lack of communication with others/isolation

\section{(1). Change in place - change in life}

All the participants in the study described their experiences of changes of their living places, from where they used to live to the current place which was the social house, which had influenced on their life and wellbeing. They described how living in the social house and taking part in daily life were concerned with the feeling of "being home lost". All the participants had experienced losing their former home, and have become homeless due to different life circumstances in their personal life. Their perceptions of being home-lost affected their current daily life and engagement in daily activities. Participants described how difficult it was to get used to and adapted to their new living conditions, for being able to take part in daily life, which most of them found it almost impossible.

They perceived their living place as social house as being different place from former one where they used to live, which was experienced as unfamiliar compared to former place where 
they used to perceive it as their home. Although participants have been living in social house for a number of years, they still felt connected to their former home and daily life. Two of the participants however experienced their current living place as different which can be considered as a variation for this finding. These participants perceived their current place as being home, where they were able to keep doing what they were willing and wishing to do, and to feel safe and secure.

\subsection{Strong feeling of being home-lost - stay connected to former home}

The participants while compared their current daily life about doing different daily activities with the previous living place, they experienced difficulties in relation to starting their daily life in social house as a new place to live, to get familiar to new people they were living with.

Participants in this study described that they compared their previous home and daily activities with the current place. For many of the participants the feeling of losing their home was related to the feeling of losing everything in life, which affected their daily life and the way they could take part in different areas of daily life. As for example, one participant mentioned:

“I lost my home... I lost everything... this isn't my home, I know that after me this room will be given to the other person..., I just live the rest of my life here..."

Six participants described their former living place to be the only and main home, where they experienced to be belonged to. Former home was perceived as a place where they able to do daily activities as they wished and wanted to do. Participants described that they were belonged to their former home and experienced to be connected with that with having good feelings and memories, and feeling of being at home. The participants perceived living in the social house as living in a not-familiar place, where they had to face with difficulties in taking part in daily activities in the way they used to. They experienced living there as being unhappy, feeling physiological and emotional pain, and not being able to involve in daily life. One participant said: “.... I feel pain when remember my home and how I lived there... I don't know anybody; everything is strange and odd to me... I don't have anyone here... I lost my life when I lost my home...."

Among the participants there were two participants that perceived living in the social house as to be living at home, and they did not experience any changes in organizing daily life and daily activities to be difficult. Experiencing to live in different places (renting apartment, living in not 
safe places) participants considered current one as a good possibility for maintaining daily life and involvement in daily occupations:

“... I've no complains, I do what I want and feel good here, this is like my home...”

They described their perception of living in social house and taking part in daily activities to be as "being at home", being free and independent in doing daily activities: like feeling free to go out, visit relatives, spent time with other in social house, and being satisfied with their daily life.

\subsection{Important to feel safe and secure}

Participants described their experiences of feeling insecure and lacking of trust towards others in daily life in social house. This had influenced their perception of living with different people to be as living with strangers. Especially in older ages they experienced additional difficulties and limitations in participation in daily activities while feeling fear, insecure:

“I don't know everybody here... I don't trust them ... even when I have to go to the toilet; I have to lock my door..."

But there were three participants that described their perception as feeling comfortable in social house as they experienced to have all necessary environmental conditions for daily living. They experienced to feel safe and be protected in daily life in social house. They experienced their daily life in social house not being significantly different from other places. Participants described their relations with others to be good and trustful and they experienced to perform desired daily activities:

"I do here what I want to do... here it is safe, nobody can come and disturb us, and I needn't afraid that one day I would be on street..."

(2) Being dependent as a doer - not free in making choices

Participants in the study experienced their living in current place as being limited in their choices and opportunities to take part in daily life. Living in social house and sharing their living place with another roommate were perceived as being restricted in to make choices in doing daily activities.

They described how they experienced to be dependent and not free in taking part in different daily activities. Only one participant experienced sharing her living place with her roommate as to be good when one's need in support in daily life. This can be considered as a variation for this finding, but however she also described separate living to be important for feeling 
good in daily life. They experienced lack of freedom and financial problems to do what they need and wish to do, being restricted to be engaged in daily life.

\subsection{Problems in sharing with others in daily living}

For all the participants sharing living environment (kitchen, toilet, and bathroom) with their neighbours was described as being not easy and pleasant, they experienced to be restricted and limited in their independence, feeling uncomfortable in doing daily activities which influenced their engagement in daily activities. For example, one participant said:

"I used to have clean environment. I clean all the time, but she (her neighbour) does not ... It is not easy to live with another person when you don't know each other very well. We are from different countries. We have different habits... it is not easy..."

Participants experienced their daily life and involvement in daily activities to be compulsory in social house. They perceived sharing the place with others in daily life to be difficult and frustrated. They described how living with others was difficult for them, while they did not have the same attitude, and had different customs in daily life especially in old ages. One of the participants experienced herself to be frustrated - not free to do activities as she wished and used to do:

“I can't do what I want to do; because that time may be she is doing other thing... it's not easy to live with other person...I have to wait...to do something..."

As a variation of these findings one participant experienced sharing her living place in social house as a good opportunity to get support and help when she needed. However, she described how having the possibility to live separately be important in daily life to be able to do daily activities in a way that one wants:

“... I am in a good relationship with my roommate, and when I need help I ask her for help... but it's better to live separate and not sharing the living place ...”

\subsection{Financial problems to do desired activities}

The participants in this study experienced having financial problems in organizing and participating in daily life in social house. Participants experienced living on a pension, without having supportive means for living to be very difficult. They described how it was limited their choices to be engaged in daily activities as they wished and want to: 
“I had a good work... and lived very well... but now... everything is changed... I can't allow myself to do what I want, I have to count everything... it is difficult to go out, to meet my friends, everything costs money..."

Participants experienced living with minimal income to limit their participation in daily life, since they had to think when and how much they can spend on food, on utilities and on other things. As for example one participant had mentioned:

"If I want to buy food... I have to decide what to buy and when... for example I like fruits ... but do not buy everything, I go to supermarket and see what is cheap... then I buy it. Meat is very expensive... but may be next month I would buy...”

\section{(3) Lack of environmental possibilities in everyday living}

The participants in this study found their engagement in daily activities to be connected with having appropriate environmental possibilities. Though, they experienced to take part in daily life as they were able but still considered to be living in not supportive and proper place. Almost

all participants emphasized the importance of needing for support for being engaged in daily life. They experienced taking part in daily activities in social house to be stressful and lacking communication with others. The participants who had physical limitations and disease experienced the need to be getting in support while taking part in daily activities.

Also, living in social house for some of the participants were perceived as to be not supportive and experienced environmental and communication difficulties in daily life. They experienced daily life in social house as feeling of being in prison. And most of the participants experienced to be alone and isolated in daily life.

\subsection{Lack of supportive environment}

Participants described the need of good living conditions to be in connection for actively and more freely taking part in daily activities. They considered living in social house to be the best opportunity for mostly healthy ones, since they manage the daily life by themselves. Living there was perceived as living in not appropriate environmental conditions. They perceived themselves to be dependent and needed in getting help to do daily activities. For example, participants experienced limited possibilities to go out and do daily activities such as outdoor activities. They experienced not only physical limitations and mobility problems, but also environmental conditions to limit their possibilities for going out from social house: 
“I have changed my living places many times... but here I don't have enough space to move, to go out ...I live in 3-rd floor and walk with the walker, I can't go up and down by the stairs ...”

All participants experienced living in social house to be compared with their past daily life and the activities they used to perform in their former place of living. Three participants described their daily living in social house to be much different from the way they used to live in their "own" home. They perceived to be limited in taking part in daily life, and they were needed to be adapted and re-change their daily life in order to confront with the structural and environmental factors in social house. They described their participation in current living place to be not comfortable and lacking opportunities for being engaged in desired daily activities: “... here there are no handles that I could hold on and go out... also the elevator does not work in the building... If I need something to buy from the shop every time I have to ask others to do that..."

\subsection{Need to be get support}

Four participants with health problems experienced getting daily help and support from others (other residents of SH, relatives) in order to do daily activities, like taking bath, doing laundry, shopping, cleaning the windows and etc. They experienced getting help and support from others was essential in their daily life:

“I can't take bath and do laundry alone... my brother's daughter came every week and help me ..."

Three participants experienced limitations in daily life for going out and doing outdoor activities (go for shopping, go for walking, visiting relatives) since they experienced health problems and environmental conditions were not supportive. They described how difficult and dangerous it could be for them to go out, as they felt insecure and afraid of falling. They experienced to get "others" help and assistance any time they need to go out:

“My roommate is sick and can't go out and do shopping. I do it for both of us... and not only for her... when I go out I usually ask if people need something to buy... it's not difficult for me to help the others... if I can do that, I am willing to be useful...”

\subsection{Lack of communication with others/isolation}

Participants experienced difficulties to communicate with residents in social house to be connected with being from the other place of origin. They experienced having language barriers in communications even though everyone were ethnic Armenians and understood Russian language (used to be common language in Armenia). However, they described how it was 
challenging communication with people who were from different place of origin. Almost all participants experienced time spending (taking part in leisure activities) in social house to be doing mostly nothing. Many of the participants had lack of opportunities to spend time with people whom they would like to, or to be engaged in their desired daily activities. One participant experienced her daily life in social house to be living in "prison". She experienced lack of possibilities to go out and communication with others, since she experienced lack of trust to others and could not find any one around to communicate with:

"The whole day I am alone... I go out, walk in corridor from one corner to another... that is it... what can I do here? There is nobody that I spend my time here with.... Also I can't go out... it feels that I am in prison..."

\section{DISCUSSION}

The following study aimed at advancing the knowledge of participation in daily occupations of older people while living in social house. The study identified three main characteristics: Change in place - change in life; being dependent as doer - not free in making choices; Lack of environmental possibilities in daily living, which described the life world of the participants and the meaning of their participation in daily occupations in the context of social house.

The current study supports the knowledge that engagement in daily occupations is vital for human-beings and, therefore, occupations have fundamental role to maintain physical and psychological health (Wilcock, 1998), wellbeing and active aging (WHO ICF-CY, 20011). At the same time home is the centre of all activities for older people (Rawles, 1978) which can facilitate or hinder participation and engagement in daily occupations, and at the same impact on their quality of life (Bowling, Bannister, Sutton, Evans et al.,2002).

The findings demonstrated how older people's participation in daily occupations was changed and restricted after living in Social House. The sense of "loosing home", was considered the main reason for living in Social House, changed the life and engagement in daily occupations of older people, remaining them to be connected to their former "home" and felt limited in daily participation. Since, older people spend much of their time in their home and home particularly important for being active in daily life, which is strongly associated with the perception of being belonged to the place of living (Adams, 2008). Previous studies (Gillsjo, 2011; Iwarsson \& Wilson, 
2006; Lilja, 2000) also showed that participation in daily occupations strongly interconnected with the perception of living place and belongingness to that place, at the same time physical environment influenced on people's ability to take part and interact with others. Literature has stressed that participation has many other aspects and can be considered as a complex concept (Haggstorm \& lund, 2008), which is combined with the subjective perception of the participation including environmental factors (Forhan, Law \& Vrikljan, 2010).

Having "safe environment" and "feeling secure" was identified by the participants to be the most important aspect in defining their participation in daily occupations and social interactions. With this finding it was described how the changes of living place influenced on the perception of "feeling of being at home - feeling of being secure", which could be considered as an important concern for people's participation and wellbeing (Kendig, Helme, Teshuva, Osborne et al., 1996). For many older people "home" and "meaning of home" not only described the physical structure of their living place, but also the psychological attachment to the place where they could "feel safe", and take part in daily life (Douglas, 1991). Perception of feeling home lost restricted participants' recognition of current living place to be their home, a place where they can feel safe and secure and this kind of perception of living environment limited their participation in daily occupations and remained them to be inactive and unprotected Therefore, it was approved that participation in daily occupations entitled with the feeling and attachment of the current place of living (Gattuso, 1996), which give an opportunity to continue daily routine and considered to be an important aspect for quality of life and successful aging (Hubbard, Tester, Downs, 2003; Zunzunegui, Alvarado, Ser \& Otero, 2003; MacDonald, Craig, Warner, 1985).

In this study "being dependent as doer - not free in making choices" characterized participants' limitations in making choices in daily participation causing to feel unhappy and dependent. From this point of view having choices give a sense of control in continuity by choosing, shaping and orchestrating daily occupations (Clark \& Jackson, 1989). At the same time, having choices to do activities strongly emphasized the importance of autonomy and selfdetermination, which were perceived as a need to have a control of own life (Hammel, 2003b). It was approved that people who have leave their home and families and move to live into another place (nursing home, social house), experienced lots of grief and loss, which were expressed in their words, actions and emotions (Harker, 1997). They very seldom have any choice to be return to the "normal" life and be free and have freedom of choices in daily occupations. 
Findings indicated that problem in sharing the living place with others limited older people's choices as a doer - lacking of choices to do activities "when" they want and "how" they want. Being dependent and not free as a doer demonstrated the subjective understanding of the meaning being able to take part and having control in daily occupations. While engagement in occupation is self-initiated and has a motive for doing and means taking control, being given the opportunity to express ourselves, structure our existence, find meaning in our life and adapt to life's challenges (Christiansen \& Townsend, 2004).

The findings of this study had identified different level of participation in daily occupations. The most important aspect was "need to be get support" in daily life, which was relatively higher among older people who had different diseases and disabilities. Lack of supportive environment (physical and social), influenced on their participation and autonomy in social house. While independence and autonomy is valued among older people and independence in daily occupation have been identified as an important aspect of health and wellbeing (Becker \& Kaufman, 1995).

Several studies showed that environmental barriers such as physical access and safety, social \& societal issues - support of family and close friends, support of professional staff/caregivers, impacted on people's participation in daily occupations (Gitlin, Mann, Machiko \& Marcus, 2001; Arvidsson, Granlund, Tyberg, 2008). In the environmental factors, social support was described as support that can come from a specific person, a specific group or the social network (Stanley \& Cheek, 2003).

When daily life is generally taken for granted and any problems connected with participation in daily occupation have been explored, living in not supportive environment has been identified as one of the reasons for being restricted from daily occupations (Rioux, 2005). Having lack of possibilities to be engaged in desired activities by him/herself, influenced on people's participation and health. From this perspective, participation and health can be viewed in a holistic way, including taking part in everyday life through engagement in daily occupations (Porn, 1993).

However, the current study found that participation in daily occupations for older people living in social house was embodied with the sense of living with others and at the same time feeling alone. Living with "others" for older people intended not to share the same attitude, values, having language barriers and accordingly having limited communication with others, stay alone, 
being isolated from others. Moreover, it is known that in residential places much of the residents' time was spent in social and emotional isolation (McKee, Harrison \& Lee, 1999). In previous studies it has been identified that in daily living especially in institutional settings, personal, cultural and structural facets served to frame the social interaction of people (Hubbard, Tester \& Downs, 2003). The importance of social participation in older age influence on the health and quality of life has been identified, including life satisfaction and emotional, subjective and psychological wellbeing (Cutrona, Russell \& Rose, 1986; Traupmann, Eckels \& Hatfield, 1992; Holmen, Ericsson \& Winbald, 1994; Rubio, Lazaro \& Sanchez-Sanchez, 2009).

Feeling alone and being isolated were connected also with changes of living place, loosing social connections with familiar people and limited possibilities to regain previous life roles. These was related to their participation in daily occupations and caused limitation in social interaction among older people, serving as bases for spending most of the time while doing nothing. Studies had approved that that institutional care settings and environmental factors can shorten levels of social interaction and social activity (MacDonald, Craig \& Warner, 1985; Bowie \& Mountain, 1993; Mattiasson \& Andersson, 1997).

Summarizing the findings of the current study, from the perspective of different levels of older people's participation and its connection to quality of life it was considered to be important having good social relationships and support, feeling safe and secure, having access and supportive environment to be engaged in daily occupation as well as having enough money to meet basic needs and participate in daily life.

\section{CONCLUSION}

This phenomenological study identified the meaning structure of participation in daily occupations among older people living in social house in Armenia. The meaning structure comprised of three main characteristics: Change in place - change in life; being dependent as doer - not free in making choices; Lack of environmental possibilities in daily living.

The findings of the study highlighted the importance of feeling of being at "home" and "belongingness" to facilitate the humans' participation in daily occupations. The lived experience of older people in participation in daily occupations was characterized with their subjective perception of the current place of living, and changes that they experienced during their life. They needed getting support in daily occupations, had limited possibilities to make their choices and 
maintain autonomy in daily occupations, and did not feel safe and protected. Moreover, they were limited in their social participation and interactions with others, felt alone and isolated.

In conclusion, the results of this study would stress the need for understanding personal perceptions of living place and environmental conditions that can facilitate or challenge older people's participation in daily occupations, while considering intervention plan and offering appropriate strategies to ensure better participation in daily occupations in current living place.

\section{LIMITATIONS OF THE STUDY}

Several limitations could be encountered in this study, which can limit the diversity of the findings and consistency of the identified meaning experiences. As main aim of the phenomenological research is to discover the meaning structure of the participants' experienced life-world of the studied phenomena, accordingly in this study- experience of participation in daily occupations is broad and multidimensional. Accordingly, the findings also could be considered to be broad, lack of specifying and deepening the understanding of participation in different areas of occupational performance: self-care, leisure, productive activities, occupational choices and roles.

The other limitation of the study was that only the experience of eight participants (7 women, one man), were presented, and gender composition was not equal in current study, at the same time all participants were from the same social house, since that was the only one in capital city of Armenia. Also conduction observation of the participation in daily occupations could provide detailed information about the phenomena and increase the credibility of the data. Consequently, further research is required to enrich the findings that identifies from this current study.

\section{IMPLICATION TO OCCUPATIONAL SCIENCE AND OCCUPATIONAL THERAPY}

The results of this study highlighted characteristics and sub-characteristics of participation to be important in old ages while living "not at home", which considered being important for facilitating older people's participation in daily occupations.

A theoretical framework can be developed to assist occupational therapists working with older people living in social house, and this kind of knowledge can also advance the understanding of participation and engagement in daily occupations from the perspective of health and wellbeing in older age. Individual experience of participation in daily occupations is essential to take into 
account when planning intervention and developing strategies for occupational adaptation in a new environment. Also the link between the social environment and the physical environment of older people are important while consideration the needs of this population in participation daily occupations.

\section{REFERENCE LIST}

1. Adams, T. (2008). Nursing people with dementia and their family members, toward the whole system approach. Dementia care nursing promoting well-being in people with dementia and their families. Basingstoke: Palgrave Macmillan.

2. Albert, S.M. (2000). The dependent elderly, home health care and strategies of household adaptation. In J.F. Gubrium \& J.A. Holstein (Eds.), Aging and everyday life (pp. 375-385). Oxford: Blackwell Publishers.

3. Arvidsson, P., Granlund, M., \& Tyberg, M. (2008). Factors Related to Self-Rated Participation in Adolescents and Adults with Mild Intellectual Disability - A systematic Literature Review. Journal of Applied research in Intellectual disabilities. Vol 21:277-291.

4. Balchin, P, \& Rhoden, M. (2002). Housing policy: an introduction. 4th edition, London.

5. Becker, G., \& Kaufman, S. (1995). Managing an uncertain illness trajectory in old age: Patients' and physicians' views of stroke. Medical Anthropology Quarterly, 9, 165-187.

6. Bowie, P., \&Mountain, G. (1993). Using direct observation to record the behaviour of longstay patients with dementia. International Journal of Geriatric Psychiatry, 8, 857-64.

7. Bowling, A., Bannister, D., Sutton, S., Evans, O., \& Windsor, J. (2002). A multidimensional model of Quality of Life in older age. Ageing and Mental Health, 6, 35571.

8. Bowling, A. (2005). Aging well: quality of life in old age. Milton Keynes, Open University Press.

9. Brundtland, G. H. (1999). Active Ageing, A Policy Framework, World Health Organization.

10. Christiansen, C.H., \& Townsend, E.A. (2004). An introduction to occupation. In C.H. Christiansen \& E.A. Townsend (Eds.), Introduction to occupation: The art and science of living. (pp.1-28). 
11. Clark, F. A., \& Jackson, J. (1989). The application of the occupational science negative heuristic in the treatment of persons with Human Immunodeficiency Infection, Occupational Therapy in Health Care, 6, 69-91.

12. Cutrona, C., Russell, D., \& Rose, J. (1986). Social support and adaptation to stress by the elderly. Journal of Psychology and Aging, 1, 1, 47-54.

13. Davison, B., Kendig, H., Stephens, F., \& Merrill V. (1993). It's my place: older people talk about their homes. Australian Government Publishing Service, Canberra.

14. DePoy, E., \& Gitlin, L. N. (1998). Introduction to research: Understanding and applying multiple strategies (2nd ed.). London: Mosby.

15. Douglas, M. (1991). The Idea of Home: A Kind of Space. Social Research, Vol. 58 (1), pp 287-307.

16. Eales, J., Keating, N., \& Damsma, A. (2001). Seniors' experiences of client centred residential care. Aging and Society.21:279-296.

17. Forhan, M.A., Law, M.C., \& Vrikljan B. H. (2010). The experience of participation in everyday occupations for adults with obesity. Can. J. OT; 77:210-8.

18. Gattuso, S. (1996). The Meaning of Home for Older Women in Rural Australia. Australian Journal on Ageng Vol 15. No 4. pp172-176.

19. Gillsjö, C. (2011). A concept analysis of home and its meaning in the lives of three older adults. Int J Older People Nurs 2011, 6(1): 4-12.

20. Gitlin, L.N., Mann, W., Machiko, T., \& Marcus, S.M. (2001). Factors associated with home environmental problems among community living older people. Disability and rehabilitation, 23: 777-787.

21. Guse, L.W., \& Masesar, M.A. (1999). Quality of life and successful aging in long-term care: Perceptions of residents. Issues in Mental health nursing 20 (6): 527-539.

22. Haak, M., Dahlin-Ivanoff S., Fange A., Sixsmith J., \& Iwarsson S. (2007). Home as the locus and origin for participation: experiences among very old Swedish people. OTJR: Occupation, Participation and Health, 27: 95-103.

23. Haak, M., Fange, A., Iwarsson, S., \& Ivanoff, S. D. (2007). Home as a signification of independence and autonomy: experiences among very old Swedish people. Scandinavian Journal of Occupational Therapy, 14: 16-24. 
24. Haak, M. (2006). Participation and independence in old age: Aspects of home and neighbourhood environments. Doctoral dissertation. Lund: Department of Health Sciences, Division of Occupational Therapy and Gerontology, Lund University, Sweden.

25. Haggstorm, A., \& Lund, M.L. (2008). The complexity of participation in daily life: a qualitative study of the experiences of person with acquired brain injury. J. Rehabil. Med; 40: 89-95.

26. Hammell, K.W. (2003b). Changing institutional environments to enable occupation among people with severe physical impairments. Using environments to enable occupational performance (pp.35-53).

27. Harker, J. (1997). Helping me to coping with the Nursing home decision. Copyright $(\mathcal{C}$ by Jean Harker

28. Holmen, K., Ericsson, K., \& Winbald, B. (1994). Loneliness and living conditions of the oldest old. Scandinavian Journal of Social Medicine, 22, 1, 15-19.

29. Zunzunegui, Alvarado, Ser, \& Otero. (2003). Aging Well Through Long-Standing Social Occupation: A Closer Look at Social Participation and Quality of Life in a Sample of Community-Dwelling Older Adults.

30. Hubbard, G. Tester, S., \& Downs, M. G. (2003). Meaningful social interactions between older people in institutional care settings. Ageing \& Society 23, 99-114.

31. Husserl, E. (Ed.). (1970). Phenomenological psychology. The Hague, the Netherlands: Martin Nijhoff.

32. Husserl, E. (Ed.). (1970). The crisis of European sciences and transcendental phenomenology. Evanstone, IL: Northwestern University Press.

33. Iwarsson, S., \& Wilson, G. (2006). Environmental barriers, functional limitations and housing satisfaction among older people in Sweden: A Longitudinal perspective on housing accessibility. Technology and disability, 18, 57-66.

34. Karlsson, G. (1993). Psychological qualitative research from a phenomenological perspective. Stockholm: Almqvist \& Wiksell International.

35. Kendig, H.L., Helme, R., Teshuva, K., Osborne, D., Flicker, L., \& Browning, C. (1996). Health Status of Older People Project: Preliminary Findings From a Survey Of the Health and Lifestyles of Older Australians. Carlton South. Victorian Health Promotion Foundation. 
36. Kielhofner, G. (2008). Model of human occupation: Theory and application (4th ed.). Baltimore: Lippincott, Williams \& Wilkins, 86-88.

37. Kvale, S. (1996). Interviews: An introduction to qualitative research interviewing. London: Sage.

38. Law, M. (2002). Participation in the occupations of everyday life. American Journal of Occupational therapy, 56(6): 640-649.

39. Lilja, M. (2000). Elderly disabled people in the home setting. Aspects of activities in daily life. Karolinska Institute, Stockholm.

40. MacDonald, A., Craig, T., \& Warner, L. (1985). The development of a short observation method for the study of the activity and contacts of old people in residential settings. Psychological Medicine, 15, 167-72.

41. Maltby, T. (2004). Ageing and the transition to retirement: a comparative analysis of European welfare states. Aldershot: Ashgate.

42. Mattiasson, A., \& Andersson, L. (1997). Quality of nursing home care assessed by competent nursing home patients. Journal of Advanced Nursing, 26, 1117-24.

43. McKee, K., Harrison, G., \& Lee, K. (1999). Activity, friendships and wellbeing in residential settings for older people. Aging and Mental Health, 3, 2, 143-52. McKinley, H. and Drew, B. 1977. The nursing home: death of sexual expression. Health and Social Work, $2,180-7$.

44. Percival, J. (2002). Domestic spaces: Uses and meanings in the daily life of older people. Ageing and Society. 22(6);729.

45. Pörn, I. (1993). Health and adaptedness. Theoretical Medicine, 14, 295-303.

46. Rawles, G.D. (1978). Prisoners of space. Boulder, Colorado: Westview Press.

47. Rioux, L. (2005). The well-being of aging people living in their own homes. Journal of Environmental Psychology, 25, 231-243.

48. Rubio, E, Lázaro, A., \& Sánchez-Sánchez, A. (2009). Social participation and independence in activities of daily living: a cross sectional study. BMC Geriatrics, BioMed Central Ltd.

49. SEU. (2006) A Sure Start to Later Life: Ending Inequalities for Older People, London: Social Exclusion Unit. 
50. Stanley, M., \& Cheek, J. (2003). Well-being and older people: A review of the literature. Canadian Journal of Occupational Therapy, 70(1), 51-59.

51. Traupmann, J., Eckels, E., \& Hatfield, E. (1992). Intimacy in older women's lives. The Gerontologist, 22, 6, 493-8.

52. United Nation Population Division, World Population Prospects, 2010, Revision

53. van Haitsma, K., Lawton, P., Kleban, M., Klapper, J., \& Corn, J. (1997). Methodological aspects of the study of behavior in elders with dementing illness. Alzheimer Disease and Associated Disorders, 11, 4, 228-38.

54. Wilcock, A. (2005). Occupational science: bridging occupation and health. Canadian Journal of Occupational Therapy, 72(1),5-12.

55. Wilcock, A. (1998). An occupational perspective of health. Thorofare: Slack Inc.

56. Wilson, H., \& Hutchinson, S. (1991). Heideggerian hermeneutics and grounded theory. Qualitative Health Research.

57. World Health Organization. (2001). The International Classification of Functioning, Disability and Health - ICF. 14-15.

58. World Health Organization. (2012). Aging and life course.

59. http://www.unfpa.am/en/aging 